\title{
Fabrication and Wear Behavior of Particulate Reinforced Metal Matrix Composites-An Overview
}

\author{
Ravi Prakash $\mathrm{M}^{1 *}$, R. Saravanan ${ }^{2}$, Madeva Nagaral ${ }^{3}$ \\ ${ }^{1}$ Research Scholar, Department of Mechanical Engineering, UVCE, Bangalore-560001 \& Assistant Professor, \\ Department of Mechanical Engineering, Oxford College of Engineering, Bangalore-560068, Karnataka, India \\ ${ }^{2}$ Assistant Professor, Department of Mechanical Engineering, UVCE, Bangalore-560001, Karnataka, India \\ ${ }^{3}$ Design Engineer, Aircraft Research and Design Centre, HAL, Bangalore-560037, Karnataka, India
}

\begin{abstract}
The composites refer to the material consisting of two or more individual constituents, in that the reinforcing particulates are embedded to the base matrix to form composite materials by improving the mechanical and tribological properties. Different types of composite materials are available and these are increasing because of their good enhanced properties, among these Metal Matrix Composites (MMCs) finds its applications in various aspects like aerospace, automotive, defense, and marine etc. These improved properties are obtained from different form of particulates which are different in their aspect ratio are mixed with base material to provide good bonding and strength between them. To obtain these enhanced properties different manufacturing techniques are followed to prepare the composites. This paper presents an overview of types of composites, different fabrication techniques available to prepare the composites and also wear behavior of particulates reinforced MMC's by studying different types of wear mechanism.
\end{abstract}

\section{Introductoion}

Engineering materials should be used in an efficient and effective way because these engineering materials are very substantial for designing and manufacturing. In the current technology the engineering materials should have best combination of properties like high strength, high stiffness, good corrosion resistance, high wear resistance, low weight, low density and less in economy also which are based on the desired applications [1-3].To meet this wide range of properties it is very much tough by using monolithic materials. Composites materials have been well known to offer such tailor made properties which are required in a wide range of applications like gears, cams, brakes, clutches, bearing etc., and hence the use of the composites is increasing rapidly in the current era.

Composite materials are also known as composition materials or commonly as composites, these composites are defined as the combination of two or more constituents materials in which one acts as base matrix and the other as reinforcement with different physical and chemical properties, so that when combined they tend to produce a different characteristics from the individual mixed elements [4]. Composites are classified into Metal Matrix Composites (MMCs), Ceramic Metal Composites (CMCs), and Polymer Matrix Composites (PMCs) based on the matrix materials. Metal matrix composites are a one of the composite material with at least two constituent parts, in that base being a metallic and the other such as ceramic materials $[5,6]$. Suppose when more than two materials are reinforced into base matrix then it is named as hybrid composites. The matrix is an continuous phase which surrounds and supports the reinforcement materials by retaining their relative positions and also it helps to produce the final shape of the composite structure by bonding with the reinforcement and also controls the strengthening, which is distributed internally at elevated temperature and different varying loads.

Some of the generally used metallic alloys are Aluminum, Magnesium, Titanium, Zinc, Cobalt, and Cobalt -Nickel alloy [7]. On the other hand the structure and the properties of these composite materials are controlled by different size (macro, micro, and nano) and different types of reinforcements which are reinforced into base matrix. The research drive from macro to nano size particles and has been enhanced extraordinarily nowadays. Owing to nano particles it increases the surface area and surface energy and supports to lead better tribological performance as compared to macro size reinforcements. This reinforcement impart there special mechanical and physical characteristics to enhance the properties of the matrix. The reinforcement surface can be coated to avoid the chemical reaction with matrix.

The MMCs uses three types of reinforcements they are particulate, fibrous, and continuous. Particulates reinforcement consists of powders such as Boron Carbide, Silicon Carbide and Aluminum Oxide etc., [8, 9]. Fibrous reinforcements include silicon carbide fiber; jute fiber etc. and finally continuous reinforcement include carbon fibers, woven carbon fiber, filament wounded etc. Generally it is believed that fibers and hard particles increase the strength and wear resistance of composites, but reductions in the ductility. Soft particles acts as lubricant but decrease the coefficient of friction, the ductility and the strength of filled matrix. The adverse 
effects of reinforcing elements and solid lubricants sometimes lead to unexpected properties of the fabricated composites. In composites the amount of matrix and reinforcement are stated either as the weight fraction, which is related to fabrication or the volume fraction which is commonly used in property calculations. Aluminum alloys are the matrix materials used in various advanced engineering applications especially in the field of aerospace, automotive, marine and structural applications, where light weight, good thermal conductivity and corrosion is majorly required [10]. These demands are met due to the improved mechanical properties, amenability to conventional handling technique and opportunity of reduction production cost of $\mathrm{Al}$ components. But however one major disadvantage of these materials is that they have low wear resistance. This drawback is due to the fact that $\mathrm{Al}$ alloy undergo wide plastic deformation and material removal under sliding wear situation because of metal to metal occurs between the solidification. Some previous investigation have reported that the wear rate performance of $\mathrm{Al}$ alloy can be decreased by introducing hard ceramic particulates such as $\mathrm{SiC}, \mathrm{B}_{4} \mathrm{C}, \mathrm{Al}_{2} \mathrm{O}_{3}, \mathrm{TiO}_{2}$ etc. These particles are distributed with uniform distribution and this distribution plays a very important role in the properties of the $\mathrm{Al} \mathrm{MMC}$ and it is improved by the intensive shearing.

The aluminum alloys are categorized into cast alloy and wrought alloy. Both these are furthered sectioned into heat treatable and non-heat treatable alloys. The wrought alloy is nominated by 4 digits number, where the first digit indicate major alloying element, the second indicated the difference of alloy, the third and fourth signifies the specific alloy in the series. The most common wrought alloy in aluminum is copper $(2 \mathrm{xxx})$, manganese (3xxx), silicon(4xxx), magnesium (5xxx), silicon and magnesium (6xxx) and zinc (7xxx) [11, 12]. The cast alloy is nominated by 3 digits and single decimal after three digits like $2 \times x .0$ and $3 \times x .1$. The digit after the decimal point takes the value of 0 and 1 which characterizes casting and ingot respectively. Pure aluminum melts at $660^{\circ} \mathrm{C}$ which makes the easy processing of AMCs through a number of fabrication techniques [13]. The various commonly used processing techniques for AMC are categorized by solid, liquid and gaseous state of materials. In case of heat treatable $\mathrm{Al}$ alloys the yield strength of composition increases after heat treatment by reducing the cracking tendency and improving the perception hardening. The major challenge related with MMC is the homogenous distribution of reinforcement particles with the matrix alloy to achieve defect free microstructure. This concern requires the careful identification of processing methods and operating parameters. Two universal methods can be used for composites productions, i.e.solid state processing and solidification processing. Both of this process has their own merits and demerits depending on the functioning parameter. The solid state process comprises powder metallurgy, high energy ball milling, diffusion bonding and various deposition techniques. On the other hand solidification process comprises two stage stir casting, compo casting, squeeze casting, in situ processing, etc.

The term wear is defined as the progressive loss of materials from surface of a dense subject due to mechanical source that is the contact with small motion against a solid, liquid, or gaseousof the counter body [14].The amount of wear is undesirable and is connected to a detrition of functionally capability. Wear damages occur when the function of the tribo system is no longer safeguarded.Wear process is the result of mechanical loading and chemical procedure may be interfacial covered on them and can also influence such loading. Wear process causes a number of materials and geometric alteration in tri biological system. The materials alteration are agreed here to mean the developmentof tri-biological reaction deposits and systematically combinations between materials of tribo elements in tribo constant.The geometrical alterations arise by the scratch of materials on the surface of subject, this causes are found to be in wear mechanism. Wear is not a physical property still it is a response, wear rate differs from $10^{-3}$ to $10^{-10} \mathrm{~N} / \mathrm{m}$ depending on the interaction condition such as counterpart material, contact pressure, sliding velocity, contact shape, environment and lubrications.

The wear rate alters through the repeated contact procedure under constant load and constant speed. It is usually great in initial unstable state and moderately lower in the later steady. Initial wear and study wear are the relations used to define wear variations causing from wear due to repeated constant. For example in case of $\mathrm{SiC}$ to $\mathrm{SiC}$ contact in water the wear rate altersfrom a high value of $10^{-6} \mathrm{~mm}^{3} \mathrm{~N} / \mathrm{m}$ to $10^{-8} \mathrm{~mm}^{3} \mathrm{~N} / \mathrm{m}$, this is caused by continuous wear of surface aspertion and better conventionality of smooth worn surface. Wear is caused by brittle nano particles in the surface grains and in later stage by tribochemical reaction. Friction is also one of the terms in tribology, friction is the mechanical force which resists moments (dynamic or kinetic friction) or hinders moment (static friction) between sliding and rolling surface.There are several types of friction like dry friction, fluid friction, lubricated friction and internal friction.The cause of external friction is beyond all the microscopic interaction point between the sliding surfaces this causes adhesion, material distortion, and grooving.The energy which is lost as friction can be measured as heat and mechanical vibration. Lubricants should reduce or avoid the micro interaction which causes the extreme part of external friction.The friction method is also related with the failure and rebonding of setting junctions and moreover it is believed that the nature of static friction is similar for both metal and polymers.Usually friction force is a function of pressure, sliding velocity, contact time, and other external friction parameters. In practice the minimal friction force is often used which is determined by the ratio of friction force to minimal contact area. 


\section{Literature Review}

Metal matrix composites can be fabricated by powder metallurgy route or stir casting method. Several investigators fabricated $\mathrm{Al}$ based composites, magnesium based composites, zinc and copper based composites. Commonly used reinforcements are carbides, oxides or nitrides in the form of particulates.

Suresh et al. [15] reported mechanical and wear behavior of stir cast $\mathrm{Al}-\mathrm{TiB}_{2}$ composites. Al6061- $\mathrm{TiB}_{2}$ composites were prepared by stir casting method. The mechanical behaviors such as hardness, tensile strength and tribological behavior were investigated. Mechanical properties were increased with increasing the content of $\mathrm{TiB}_{2}$ in Al6061 alloy. Wear resistance of $\mathrm{TiB}_{2}$ reinforced composites were enhanced.

Rajmohan et al. [16] studied mechanical and wear properties of aluminium hybrid metal matrix composites. Mica and SiC particulates reinforced A356 alloy composites were prepared by stir casting method. The mechanical and wear properties of hybrid composites were investigated. Al-10SiC-3Mica hybrid composites shown better mechanical and wear properties compared to base alloy.

Baradeswaran et al. [17] investigated the mechanical and wear properties of $\mathrm{Al} 7075-\mathrm{Al}_{2} \mathrm{O}_{3}$-graphite hybrid composites. The investigation reveals the effectiveness of incorporation of graphite in the composite for gaining wear reduction. The $\mathrm{A} 17075$ reinforced with $\mathrm{Al}_{2} \mathrm{O}_{3}$-graphite were investigated. The composites were fabricated by using liquid metallurgy route. The $\mathrm{Al} 7075-\mathrm{Al}_{2} \mathrm{O}_{3}$-Graphite hybrid composite was prepared with 5 wt. \% graphite particles addition and 2, 4, 6 and 8 wt. $\%$ of $\mathrm{Al}_{2} \mathrm{O}_{3}$. The hardness, tensile strength, flexural strength and compression strength of the $\mathrm{Al} 7075-\mathrm{Al}_{2} \mathrm{O}_{3}$-graphite hybrid composites are found to be increased by increased weight percentage of ceramic phase. The wear properties of the hybrid composites containing graphite exhibited the superior wear resistance properties.

Linlin et al. [18] investigated mechanical and tribological behavior of aluminium metal matrix composites reinforced with in situ $\mathrm{AlB}_{2}$ particles. Composites were prepared by hot rolling and solution treatment. Mechanical properties like tensile and micro hardness measurements were evaluated. The friction co-efficient, wear behavior and scratch morphology of the MMCs and pure aluminium were studied. The tensile, hardness and wear properties are higher in case of composites compared to unreinforced $\mathrm{Al}$ alloy.

Harichandran and Selvakumar [19] carried out experiments on nano and micro $\mathrm{B}_{4} \mathrm{C}$ reinforced pure aluminium matrix composites. The micro and nano composites containing different weight percentages of $\mathrm{B}_{4} \mathrm{C}$ particles were fabricated by stir and ultrasonic cavitation assisted casting process. Tensile, hardness, impact and wear tests were carried out to evaluate mechanical properties of the micro and nano composites. The properties were enhanced in the case of $\mathrm{B}_{4} \mathrm{C}$ reinforced composites compared to $\mathrm{Al}$ alloy matrix.

\section{Types Of Composites}

Based on the type of matrix used to prepare the composites, have been classified into the following types.

\subsection{Polymer Matrix Composites}

Polymers make ideal materials as they can be processed easily, possess lightweight, and desirable mechanical properties. Polymer matrix composites are also known as FRP - Fiber Reinforced Polymers (or Plastics). These materials use a polymer-based resin as the matrix, and a variety of fibers such as glass, carbon and aramid as the reinforcement.Two main kinds of polymers are thermosetand thermoplastics [20]. Thermosets have qualities such as a well-bonded three-dimensional molecular structure after curing. They decompose instead of melting on hardening. Merely changing the basic composition of the resin is enough to alter the conditions suitably for curing and determine its other characteristics. They can be retained in a partially cured condition too over prolonged periods of time, rendering thermosets very flexible. Thus, they are most suited as matrix bases for advanced conditions fiber reinforced composites. Thermosets find wide ranging applications in the chopped fiber composites form particularly when a premixed or moulding compound with fibers of specific quality and aspect ratio happens to be starting material as in epoxy, polymer and phenolic polyamide resins.

Thermoplastics have one- or two-dimensional molecular structure and they tend to at an elevated temperature and show exaggerated melting point. Another advantage is that the process of softening at elevated temperatures can reversed to regain its properties during cooling, facilitating applications of conventional compress techniquesto mould the compounds.

\subsection{Metal Matrix Composites}

Metal matrix composites, at present though generating a wide interest in research fraternity are not as widely in use as their plastic counterparts. High strength, fracture toughness and stiffness are offered by metal matrices than those offered by their polymer counterparts [21]. They can withstand elevated temperature in corrosive environment than polymer composites. Most metals and alloys could be used as matrices and they require reinforcement materials which need to be stable over a range of temperature and non-reactive too. However the guiding aspect for the choice depends essentially on the matrix material. Light metals form the matrix for temperature application and the reinforcements in addition to the after mentioned reasons are characterized by high modulus. 
Most metals and alloys make good matrices. However, practically, the choices for low temperature applications are not many. Only light metals are responsive, with their low density proving an advantage. Titanium, aluminium and magnesium are the popular matrix metals currently in vogue, which are particularly useful for aircraft applications. If metallic matrix materials have to offer high strength, they require high modulus reinforcements. The strength-to-weight ratios of resulting composites can be higher than most alloys. The melting point, physical and mechanical properties of the composite at various temperatures determine the service temperature of composites. Most metals, ceramics and compounds can be used with matrices of low melting point alloys. The choice of reinforcements becomes more stunted with increase in the melting temperature of matrix materials.

\subsection{Ceramic Matrix Composites}

Ceramics can be described as solid materials which exhibit very strong ionic bonding in general and in few cases covalent bonding. High melting points, good corrosion resistance, stability at elevated temperatures and high compressive strength, render ceramic-based matrix materials a favorite for applications requiring a structural material that doesn't give way at temperatures above $1500^{\circ} \mathrm{C}$. Naturally, ceramic matrices are the obvious choice for high temperature applications. High modulus of elasticity and low tensile strain, which most ceramics posses, have combined to cause the failure of attempts to add reinforcements to obtain strength improvement. This is because at the stress levels at which ceramics rupture, there is insufficient elongation of the matrix which keeps composite from transferring an effective quantum of load to the reinforcement and the composite may fail unless the percentage of fiber volume is high enough. A material is reinforcement to utilize the higher tensile strength of the fiber, to produce an increase in load bearing capacity of the matrix. Addition of high-strength fiber to a weaker ceramic has not always been successful and often the resultant composite has proved to be weaker. The use of reinforcement with high modulus of elasticity may take care of the problem to some extent and presents pre-stressing of the fiber in the ceramic matrix is being increasingly resorted to as an option. When ceramics have a higher thermal expansion coefficient than reinforcement materials, the resultant composite is unlikely to have a superior level of strength. In that case, the composite will develop strength within ceramic at the time of cooling resulting in micro-cracks extending from fiber to fiber within the matrix. Micro-cracking can result in a composite with tensile strength lower than that of the matrix.

\section{Types Of Fabricatioin Techniques}

A key task in the processing of composites is to gain uniform homogenous distribution of the reinforcement in the matrix phase and to succeed the defect free microstructure. This subject requires the careful identification of processing techniques and operating parameters. Based on the shape of the reinforcing phase in composites may be either fibers or particles. Two generic processes can be used for the manufacturing of the composites that is liquid state process and solid state process. Liquid state process includes stir casting, compocasting, squeeze casting, spray casting, ultrasonic assisted casting and in situ processing [22, 23]. On the other hand solid state processing includes powder metallurgy route, diffusion bonding, and friction stir process.

\subsection{Stir Casting}

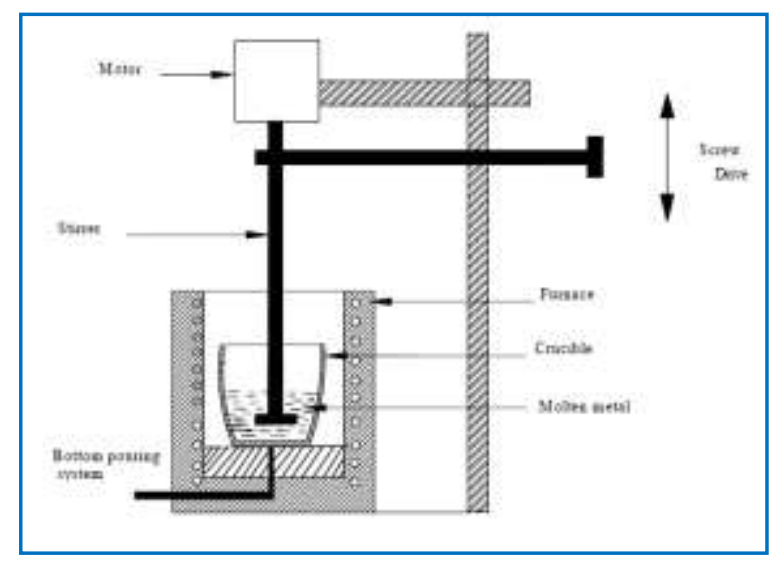

Fig. 1: Stir casting method

Stir casting is the primary process of composites production. In stir casting, a reinforcement phase in the form of ceramics, particles, fibers are mixed with the molten metal matrix by the two stage mechanical stirring process which forms a vortex method. The matrix material is heated to its maximum temperature so that metal is completely melted to molten stage. Once it is melted then preheated particles are reinforced in steps of two stages and mixed thoroughly with stirrer and poured into the preheated mould and allowed to solidify. The 
efficiency of two-step process is mainly credited to its ability to break the gas layer around the surface of the particle and to provide homogenous distribution of the particles. Stirring speed, stirring temperature, preheating temperature of mould and reinforcement, addition of magnesium (to enhance the wettability), stirring time, blade angle, inert gas, and powder feeding rate are some of the processing parameters which are very essential that lead to the better improved characteristic of composite material. Fig. 1 shows the stir casting set up.

\subsection{Compo Casting}

Compo casting is carried at low temperature and low pressure compared to squeeze casting. It is a liquid state method in which the reinforcement elements are added to the solidifying melt while being vigorously disturbed. It has been shown that the primary solid particles already shaped in the semi-solid slurry can mechanically capture the reinforcing elements, avoid the gravity segregation, and decrease their agglomeration and helps in avoidance to solve the wettability difficult at the matrix reinforcement boundary. Due to this it will results in enhanced distribution of the reinforcement elements. Compo casting method composed with rheocasting and thixoforming suitable to the group of semi-solid forming (SMF) which includes hypo eutectic and hyper eutectic alloys in semi-solid state.

\subsection{Sqeeze Casting}

The oldest and the most frequently used method till today in automotive sector is the squeeze casting process. It is generally known as squeeze casting infiltration or pressure die infiltration. This process is the mixture of gravity die molding and closed die forging. Squeeze casting is a forced infiltration method of a liquid stage production of MMCs, by using a portable mould portion for smearing pressure on the molten metal and strengthen it to penetrate into a performed dispersed phase which is located in the lower permanent mould part. Because of the close contact between the fluid metal and the mold edge, premium casting is got, and offers high metal yield, less shrinkage porosity, good surface finish and low operating coast. A typical characteristic of this method is that the change from liquid to solid stage is very quick. The process is basically separated into two types direct and indirect; in the direct process the squeeze pressure is applied through the die casting punch itself, but where as in indirect process the squeeze pressure is applied after closing of the die with the help of secondary ram.

\subsection{Powder Metallurgy}

Powder metallurgy is the process of blending fine powdered materials, pressing them into preferred shape, and then heating the compressed material in a controlled atmosphere to bond the material.The powder metallurgy comprises four basic steps: i. powder manufacturing ii. powder mixing and blending iii. compacting iv. sintering as shown fig 2. Compacting is normally achieved at room temperature and the elevated temperature of sintering process is typically conducted at atmospheric pressure. Better mechanical properties are obtained by this technique because the powder is not melted. Powder metallurgy is tremendously evolved method of manufacturing reliable net shaped components which is very coast effective in producing simple or complex parts. Some of the following benefits of powder metallurgy route; production of complex shapes to a very close dimensional tolerance with minimum scrap loss and less secondary process, both physical and mechanical properties can be personalized by the having the control over the process parameters. But nevertheless this process requires alloy powder which are usually more expensive than bulk material and includes complicated process, thus powder metallurgy does not suits for mass production.

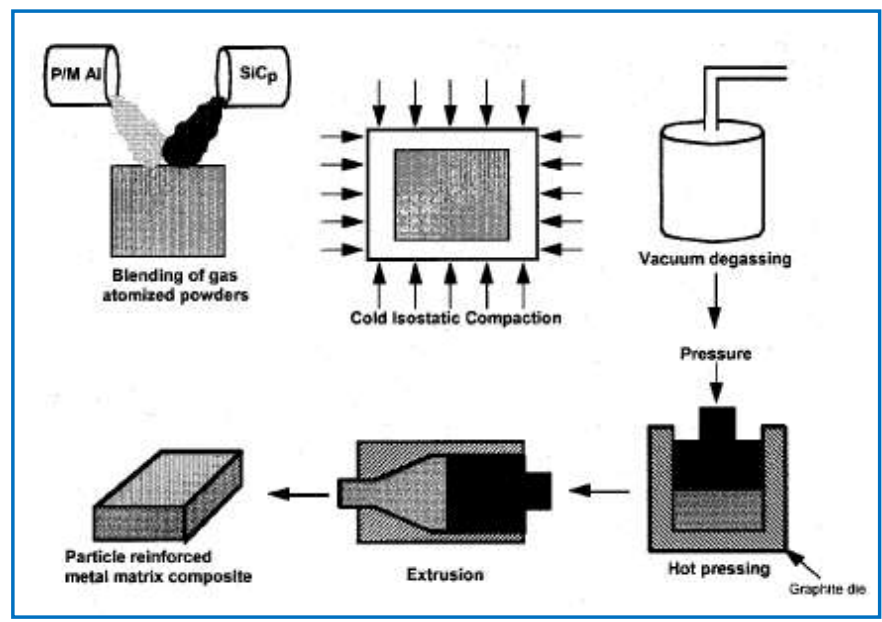

Fig 2: Powder processing, hot pressing and extrusion process for fabricating particulate reinforced MMCs. 


\subsection{Diffusion Bonding}

It is a one of the common solid state processing technique for joining similar and dissimilar metals. Inter diffusion of atoms between clean metallic surface at a higher temperature leads to good bonding. The primary advantage of this technique is the capacity to process a wide variety of metal matrices and control of fiber alignment and volume fraction. Diffusion bonding of foils is a prime process which is used for the fabrication of composites wherein the layers of metallic foils and ceramic monofilament fibers are alternatively arranged to produce precursor materials for successive diffusion bonding.

\subsection{Friction Stir Process}

Nano reinforcement in a uniform fashion is the major and critical task. It should be noted that the current processing technique for forming surface composites are founded on liquid phase processing at great temperature. But FSP is a solid state technique process in which we obtain a fine grained microstructure. This process is carried out as similar approach done in friction stir welding (FSW), in which a non consumable revolving tool with particularly designed pins and shoulder is plunged into the interface between two plates to join and traversed along the line of joint. Localized heating is formed by the friction between the rotating tool and the work piece to raise the indigenous temperature of the material to the range where it can be plastically deformed easily. It is well known that the stirred region consists of well and equiaxed grains produced due to vibrant crystallization.

\subsection{Wear and Friction}

\section{Wear}

Wear cannot be told as a material property, but nevertheless it is a system response. The term wear is coined as the progressive loss of material from the surface of a hard subjected due to the mechanical reasonsthat is the interface with and a frictional motion against a solid, liquid, and gaseous counter body. The loss of the material or the wear rate can be varied from $10^{-3}$ to $10^{-20}$ depending on the certain situation like sliding velocity, speed, load, type of the lubrication used, type of the materials used, and also the condition of the environment in which the wear test is conducted. The wear loss is occurred when the function of the tribosystem is no longer safeguarded and it is in the form of microcracks or localized plastic deformation. Different types of wear are adhesive wear, abrasive wear, surface fatigue, fretting, tribo-chemical reaction and erosive wear which are all categorized on the basis of motion, tribological loading and materials response and reaction [24]. Wear is a complex phenomenon which results because of the mechanical loading, in which the load is applied on to the surface and it will be conveyed through the point of the contact, and it also depends on the chemical process which is inter facially super imposed between the two mating tribo-surfaces. Material and geometric alteration are caused by the wear process in the field of tribological system. The wear loss of the material can be measured in the practice of weight loss and volume loss; the wear rate can also be determined with the help of appropriate intrinsic properties like load, speed, temperature etc. Initial wear and steady wear are the two terms that are used to define wear rate changes; in the early stage if the wears test, the wear rate will be high which is caused by brittle microstructure in surface of the grains and later by the tribo-chemical reaction. Some of the commonly and available procedures which are used to conduct wear test are pin on disc, pin on flat, pin on cylinder, pin into bushing, rectangular flats on rotating cylinders based on the desired application which are to be tested.

Another important term in the field of tribology is the friction. The first rule of sliding friction was discovered by Leonardo da Vinci in 1493 which was unpublished, later those rules were rediscovered by Guillaume Amontons in 1699. Friction is the mechanical force, resisting the relative or hinders moment between the solid surface, fluid layers, and material elements which are sliding against each other. These forces of friction are called external friction. On the other hand the internal friction as the part of external friction, in which the force resisting motion between the elements making up a solid material while it undergoes deformation, i.e. is described as viscosity. So therefore when the surface which in contact moves with relative to each other, the friction occurs between the surfaces and converts kinetic energy to thermal energy. The best example which illustrates this sequence is the rubbing of the wood each other which creates the friction and results in spark of fire. Various different types of friction are dry friction, fluid friction, lubricated friction, and skin friction. The energy which is vanished as friction can be stated as the heat or the mechanical vibration. Different lubricants are used to reduce and to avoid the micro contact which is caused throughout the friction. The friction force is denoted by $\mathrm{F}$ and it is the function of load, sliding velocity, temperature, contact time and many other friction parameters. In general the nominal friction force is used and it is defined as the ratio of friction force to the normal geometric interface area $f_{n=} F_{f} / S_{N}$. The law of dry friction was stated on Amontons first and second law and also Coulombs law of friction. 


\subsection{Wear Types}

Wear condition arises when there is relative motion between two solids under influence of the load, the motion can either sliding or rolling i.e. unidirectional or there are chances of combination of both rolling and sliding and also along with movement of oscillation at a small amplitude. Not only on the movement involved or on the influence tribological loading the wear modes also depends on the particular of the materials concerned, the following types of wear have been classified as abrasive wear, adhesive wear and surface fatigue wear which are briefly explained as follows.

\subsubsection{Abrasive Wear}

In abrasive wear, the material loss from the surface is caused by sliding abrasives particles in the form of wear debris under the effect of load and also from the dust particles from the surrounding which remain trapped while sliding and lead to the causes for the loss of material. The former is known as two body abrasion and latter it is called third body abrasion with the loose abrasive particles called third bodies. For example rubbing our shoes, wear is by both two and three body abrasion, rubbing on rough concentrate yields two body abrasions by fixed particles, and mean while dirt particles between your soles and flooring or walkways create three body abrasions. But usually two body abrasion is more severe. In industrial conditions abrasive wear is wide spread; in fact it has been predictable that about $50 \%$ of wear is faced in industry is by abrasion mechanism. As a consequence different types of abrasive wear are distinguished in practice i.e. is two body low stress abrasion and three or high stress abrasion, these two types of abrasive wear is defined on the basis on the degree of stress in the surface of metal or the number of constituents involved. Two Body Low Stress AbrasionBelow the low stress situation abrasive particles sliding against a metal surface origins fine scratches or micro cuts, forming small chips as lost material. These chips are finally generated from the up-features of the grooves, but the metal removal mechanism is similar to that of grinding. ASTM G 65 enumerates the dry sand wheel experiment which simulates the low stress abrasion. Three Body or High Stress Abrasion- The abrasive particles which are forced between two mating faces, high stress abrasion arises leading to material loss from both workings surfaces. This kind of abrasion occurs in moving parts on tracks for bulldozers and earthmoving equipment. Grooves are plowed in the material from the severe edges of abrasive and chips are designed. The main variables disturbing abrasive wear rate are angle of attack, sliding distance, load, and hardness of material. Fig. 3 showing the abrasive wear mechanism.

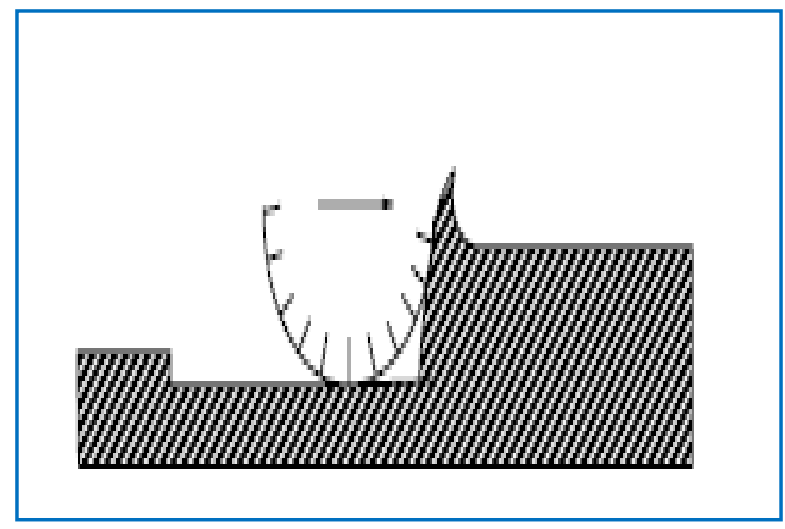

Fig. 3: Abrasive wear

\subsubsection{Adhesive Wear}

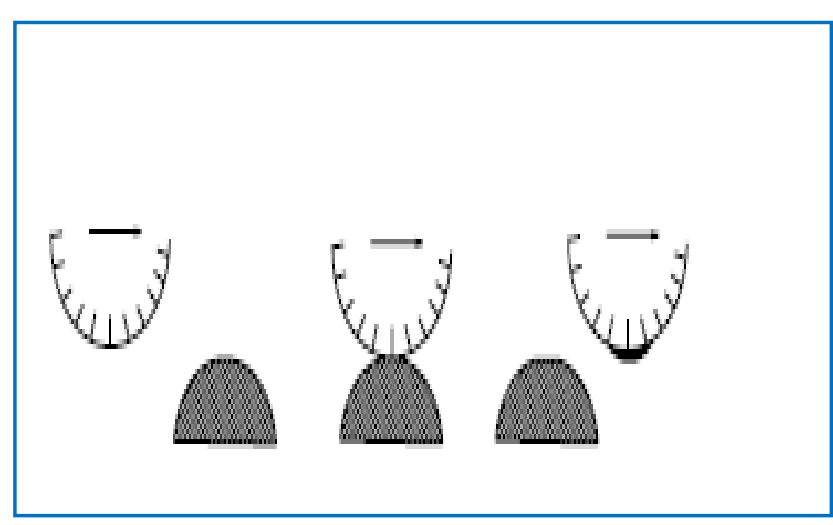

Fig.4: Adhesive Wear 
In this the relative movement can be unidirectional or reciprocating sliding or interface occurring under small amplitude oscillatory contact under load (fig. 4). The mating faces points are recognized to flow plastically and to form strong work tough junction. Wear by this mechanism is severe and can happen in the kinematic chain of a machine whenever there is an absence of effective lubrication at the interference of two bodies in interaction. For similar metals the junction formed among severities is tougher than that of parent metals because of work hardening during the sliding process, so the material lost through removal of lumps from each or both mating surfaces. For dissimilar metals when the welded severity junction is shared part of the weaker metal is lost. And the adhesive wear of dissimilar pairs is generally lower than for similar metal pairs. The test on adhesive wear are based in the following three practices, they are; pin on disc as per ASTM G 99, pin on ring as per ASTM G 77, and pin on plate. In adhesive wear different forms of wear are formed based on the macroscopic growth as discussed. Firstly, when the adhesive wear becomes severe it leads to galling this type of wear is considered by the formation of macroscopic growths. On the other hand scuffing and scoring are the moderates forms of adhesive wear which are described by scratches or by surface distortion associated with course of motion. When scoring occurs it leads to very high wear rate so this form of wear as to be avoided. The last and least severe form of adhesive wear is the mild wear which is also known as oxidative wear. This kind of wear starts by adhesion at the real areas of mating surfaces, then wear particles designed and with frequent rubbing of these particles react with environment and typically forms an oxide.

\subsubsection{Surface Fatigue}

Surface fatigue (fig. 5) appears to be a moderately simple wear mechanism since it seems to be based only on the action of stress on the surfaces without the need of direct physical solid contact of the surface under consideration. Apart from static loading alternating mechanical loading can also occur in tribological arrangements and may be described as periodic oscillation. So fatigue wear arises because of cyclic loading, these results in weakening of the surface strength, crack initiation and propagation above or below the surface. For example in rolling components bearings and loss of material arises by spalling of surface layers. Since surface fatigue is the classic failure kind of rolling contact, as in ball and roller bearing the mechanism of surface fatigue in rolling contact will be considered first. Associating the surface fatigue if rolling interacts with the ordinary fatigue of bulk material there are two modifications to be noted. Firstly the variations in the time to failure, the lifetime are much severe in rolling contact. Second is the important phenomena of fatigue limit stress which is observed in ordinary bulk testing, i.e. there exists a certain stress limit for a given materials beneath which the material enjoys an infinite fatigue life. Although there has been substantial progress in the calculation progress of rolling stresses distribution, a combine of influencing factors must be considered. Some of the following factors which adjust the nominal contact stress distribution from that figured for homogenous, isotropic, elastic, smooth surface materials in dry rolling contact.

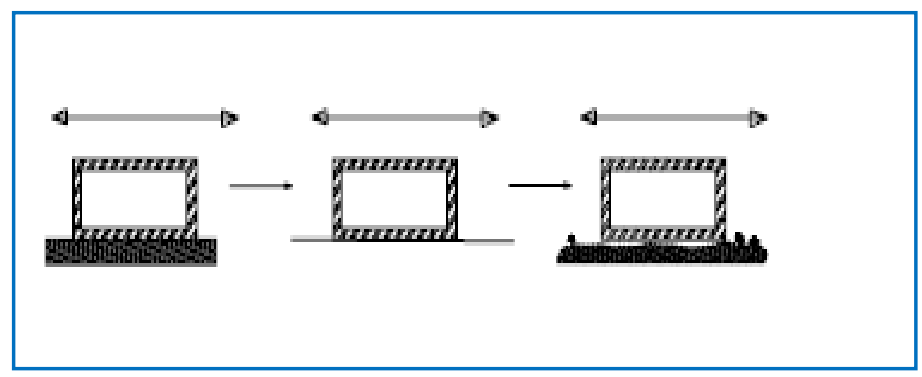

Fig.5: Surface Fatigue Wear

\subsubsection{Erosive Wear}

Erosive wear (fig. 6) can be defined as the process of metal removal due to impingement of solid particles on a surface. Erosion is caused by a gas or a liquid, which may or may not carry, entrained solid particles, impinging on a surface. When the angle of impingement is small, the wear produced is closely analogous to abrasion. When the angle of impingement is normal to the surface, material is displaced by plastic flow or is dislodged by brittle failure.

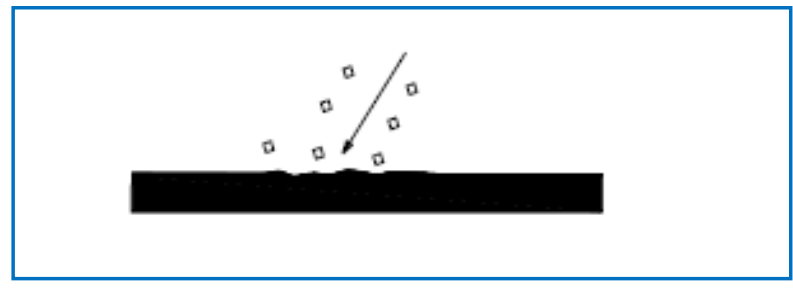

Fig. 6: Erosive Wear 


\subsubsection{Corrosive Wear}

Corrosion wear (fig. 7) is the gradual eating away or deterioration of unprotected metal surfaces by the effects of the atmosphere, acids, gases, alkalis, etc. Most metals are thermodynamically unstable in air and react with oxygen to form an oxide, which usually develop layer or scales on the surface of metal or alloys when their interfacial bonds are poor. This type of wear creates pits and perforations and may eventually dissolve metal parts.

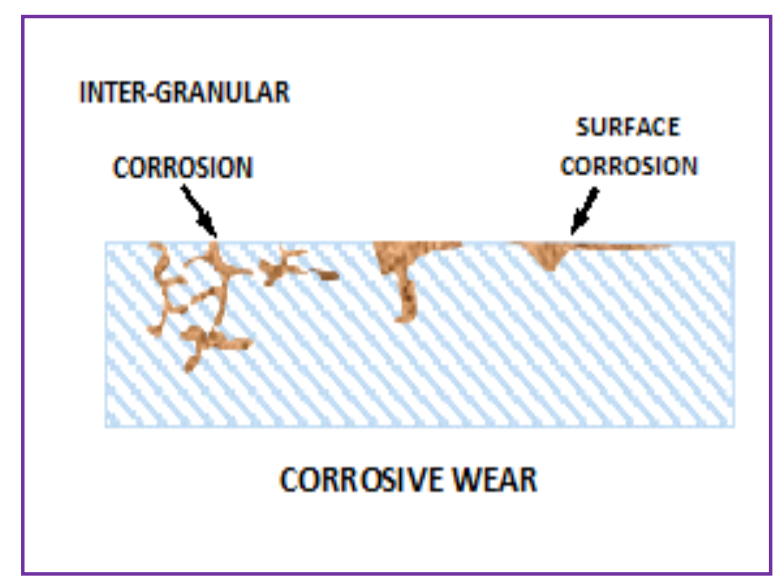

Fig.7: Corrosive Wear

\section{Applications}

By lower production costs and the attraction about savings in weight the MMC application has increased more and more about the car field and not only about the competition. This is due to the major properties at high working temperature that have made the material composite an interesting alternative to traditional materials. In fact there is an increasingly important MMC presence about engines (engine block and pistons), drive shaft and disc brakes (including rail type). For example for the brake systems, the MMC application concerns especially the discs that are produced by aluminium matrix reinforced by $\mathrm{SiC}$ particle [25]. There are used in Piston rods and connecting rods. Silicon carbide particles have excellent wet ability characteristics with $\mathrm{Al}$ and thus provide interface bonding with $\mathrm{Al}$ after freezing of the casting. The silicon carbide particulars improves the wear resistance and hence the life of the parts.

New generation advanced integrated circuits are generating more heat than previous types. Therefore, the dissipation of heat becomes a major concern. Indeed, thermal fatigue may occur due to a small mismatch of the coefficient of thermal expansion between the silicon substrate and the heat sink (normally molybdenum). This problem can be solved by using MMCs with exactly matching coefficients (e.g. Al with boron or graphite fibers and $\mathrm{Al}$ with $\mathrm{SiC}$ particles). Besides a low coefficient of thermal expansion and a high thermal conductivity, these Al-based MMCs also have a low density and a high elastic modulus.Hermetic package materials are developed to protect electronic circuits from moisture and other environmental hazards. These packages have often glass-to-metal seals. Therefore, materials with an "adjustable" coefficient of thermal expansion are required. Al-based MMCs are fulfilling this condition, as the coefficient of thermal expansion is depending upon the volume fraction of the fibers or particles. These components are not only significantly lighter than those produced from previous metal alloys, but they provide significant cost savings through netshape manufacturing. MMC is also used for thermal management of spacecraft power semiconductor modules geosynchronous earth-orbit communication satellites, displacing $\mathrm{Cu} / \mathrm{W}$ alloys with a much higher density and lower thermal conductivity, while generating a weight savings of more than $80 \%$. These modules are also used in a number of land-based systems, which accounts for an annual production near one million piece-parts. With these demonstrated benefits, application of MMCs for electronic packages will continue to flourish for space applications.

\section{Conclusions}

Now a day's micro particulate reinforced metal matrix composites are widely used in military and aerospace applications. Several matrix materials are available as a matrix. Among all the matrix materials aluminium, magnesium and zinc are the most popular materials. Micro particulates like $\mathrm{Al}_{2} \mathrm{O}_{3}$, graphite; $\mathrm{B}_{4} \mathrm{C}$, $\mathrm{TiC}, \mathrm{TiO}_{2}$ and $\mathrm{WC}$ can be used as the reinforcements. In processing of metal matrix composites, several techniques like solid and liquid state methods are used. Among all the fabrication techniques liquid stir casting process is the more simpler and economical one. For most of industrial applications wear plays important role. The materials should possess good wear resistance for durability of assemblies. 


\section{Refernces}

[1]. NarayanaYuvaraj, SivanandanAravindan and Vipin, "Fabrication of Al5083/B ${ }_{4} \mathrm{C}$ surface composite by friction stir processing and its tribological characterization", Journal of Materials Research and Technology, 4 (4), pp. 398-410, 2015.

[2]. GurdialBlugan et al., " $\mathrm{Si}_{3} \mathrm{~N}_{4}-\mathrm{TiN}-\mathrm{SiC}$ three particle phase composites for wear applications", Ceramics International, 40, pp. 1439-1446, 2014.

[3]. M. Khakbiz and F. Akhlaghi, "Synthesis and structural characterization of $\mathrm{Al}-\mathrm{B}_{4} \mathrm{C}$ nano composite powders by mechanical alloying", Journal of Alloys and Compounds, 479, pp. 334-341, 2009.

[4]. Syed NasimulAlam and Lailesh Kumar, "Mechanical properties of aluminium based metal matrix composites reinforced with graphite nanoplatelets", Materials Science \& Engineering A, pp. 16-32, 2016.

[5]. B. N. Sarada, P. L. Srinivasa Murthy, G. Ugrasen, "Hardness and wear characteristics of hybrid aluminium metal matrix composites produced by stir casting technique", Materials Today, Proceedings, 2, pp. 2878-2885, 2015.

[6]. Ajay Singh Verma, Sumankant, Narender Mohan Suri and Yasphal, "Corrosion behavior of aluminium base particulate metal matrix composites”, Materials Today Proceedings, 2, pp. 2840-2851, 2015.

[7]. C. S. Ramesh, A. C. Vijetha, Nirupama Mohan and Harsha G Gudi, "Slurry erosion wear of Al6061 SiC composites developed by hybrid technique", Applied Mechanics and Materials, 592-594, pp. 734738, 2014.

[8]. MadevaNagaral, V. Auradi and S A Kori, "Dry sliding wear behavior of graphite particulate reinforced Al6061 alloy composites materials”, Applied Mechanics and Materials, 592-594, pp. 170-174, 2014.

[9]. Rajaneesh N Marigoudar and KanakappaSadashivappa, "Dry sliding wear behavior of SiC particles reinforced Zinc-Aluminium (ZA43) alloy metal matrix composites", Journal of Minerals \& Materials Characterization \& Engineering, 10, 5, pp. 419-425, 2011.

[10]. M. Leiblich et al., "Subsurface modifications in powder metallurgy aluminium alloy composites reinforced with intermetallic $\mathrm{MoS}_{2}$ particles under dry sliding wear", Wear, 309, pp. 126-133, 2014

[11]. K. Umanath, K. Palanikumar, S. T. Selvamani, "Analysis of dry sliding wear behavior of Al6061-SiC$\mathrm{Al}_{2} \mathrm{O}_{3}$ hybrid metal matrix composites", Composites Part-B, 53, 2013, pp. 159-168.

[12]. XinGao et al., "Preparation and tensile properties of homogeneously dispersed graphene reinforced aluminium matrix composites", Materials and Design, 94, pp. 54-60, 2016.

[13]. B. VijayaRamnath, C. Elanchezhian, M. Jaivignesh, S. Rajesh, C. Parswajinan, "Evaluation of mechanical properties of aluminium alloy -alumina-boron carbide metal matrix composites", Materials and Design, 58, 2014, pp. 332-338.

[14]. S. Baskaran, V. Anandkrishnan, MuthukannanDuraiselvam, "Investigations on dry sliding wear behaviour of in situ casted AA7075-TiC metal matrix composites by using Taguchi Technique", Materials and Design, 60, 2014, pp. 184-192.

[15]. S. Suresh, N. ShenbagaVinayagaMoorthi, S. C. Vettivel, N. Selvakumar, "Mechanical behavior and wear prediction of stir cast $\mathrm{Al}_{-} \mathrm{TiB}_{2}$ composites using response surface methodology", Materials and Design, 59, 2014, pp. 383-396.

[16]. T. Rajmohan, K. Palanikumar, S. Ranganathan, "Evaluation of mechanical and wear properties of hybrid aluminium matrix composites", Transactions of Nonferrous Metals Society of China, 23, 2013, pp. 2509-2517.

[17]. A. Baradeswaran, A. ElayaPerumal, "Study on mechanical and wear properties of $\mathrm{Al}^{7} 075-\mathrm{Al}_{2} \mathrm{O}_{3}$ graphite hybrid composites", Composites Part B, 56, 2014, pp. 464-471.

[18]. Linlin Yuan, Jingtao Han, Jing Liu and Zhengyi Jiang, "Mechanical properties and tribological behavior of aluminium matrix composites reinforced with in situ $\mathrm{AlB}_{2}$ particles", Tribology International, 98, pp. 41-47, 2016.

[19]. R. Harichandran and N. Selvakumar, "Effect of nano/micro B4C particles on the mechanical properties of aluminium metal matrix composites fabricated by ultrasonic cavitation assisted solidification process", Archives of Civil and Mechanical Engineering, 16, pp. 147-158, 2016.

[20]. Shisheng Li, Yishi Su, Xinhai Zhu, Huiling Jin, QuibaoOuyang and Di Zhang, "Enhanced mechanical behavior and fabrication of silicon carbide particles covered by in situ carbon nano tube reinforced 6061 aluminium matrix composites", Materials and Design, 107, pp. 130-138, 2016.

[21]. XinGao et al., "Preparation and tensile properties of homogeneously dispersed graphene reinforced aluminium matrix composites", Materials and Design, 94, pp. 54-60, 2016.

[22]. Hamid, R. E., Seyed, A.S., Mohsen, H.S. and Yizhong, H.: Investigation of microstructure and mechanical properties of Al6061 nanocomposite fabricated by stir casting, Materials and Design, Vol. 55, pp. 921-928, 2014 
[23]. MadevaNagaral, Pavan R, Shilpa P S and V Auradi, "Tensile behavior of $\mathrm{B}_{4} \mathrm{C}$ particulate reinforced Al2024 alloy metal matrix composites", FME Transactions, 45, 1, 93-96, 2017.

[24]. Sajjadi, S. A., Ezatpour, S.R. and Beygi, H.: Microstructure and mechanical properties of Al-Al2O3 composites fabricated by stir casting, Materials Science and Engineering A, Vol. 528, pp. 8765-8771, 2011.

[25]. Hashim, J., Looney, L. and Hashmi, M.S.J.: Metal matrix composites production by the stir casting method, Journal of Materials Processing Technology, Vol. 92-93, pp. 1-7, 1999. 